\title{
The Impact of Leader's Cultural Intelligence on Organizational Commitment
}

\author{
Roya Anvari ${ }^{1}$, Sobia Irum ${ }^{1}$, Muhammad Ashfaq ${ }^{1} \&$ Dauda Mohammed Atiyaye ${ }^{1}$ \\ ${ }^{1}$ Department of Human Resource Development, Faculty of Management, Universiti Teknologi Malaysia, \\ Malaysia
}

Correspondence: Roya Anvari, Department of Human Resource Development, Faculty of Management, Universiti Teknologi Malaysia, Malaysia. Tel: 60-17-245-8894. E-mail: roya.anvari@utm.my

Received: March 5, 2013 Accepted: June 19, 2014 Online Published: August 20, 2014

doi:10.5539/ass.v10n17p45 URL: http://dx.doi.org/10.5539/ass.v10n17p45

\begin{abstract}
Previous studies have consistently shown that Cultural Intelligence (CQ) is an important skill in today's organizations. The literature on leadership suggests that CQ has the potential to increase both employee commitment and organizational outcomes. This study is a survey related to leadership style at organizations. The research attempts to investigate how leaders affect staff's Organizational Commitment (OC). We found that there is a significant relationship between leaders' CQ who operates with meta-cognitive, cognitive, motivational, and behavioral with OC. Moreover, the quality of leadership within an organization had an effect on the OC.
\end{abstract}

Keywords: leadership, cultural intelligence, organizational commitment

\section{Introduction}

Leadership is considered as the core heart of organization and employee performance is attributed to its leadership. Thus, the organizational success or failure depends upon the way, the kind of leadership which has been provided to its members (Bodla, 2010). Leadership particularly refers to managers who are mainly concerned with the strategy formulation at overall organizational level (Pieterse et al., 2010; Berson et al., 2006). Leaders are supposed to be have direct effect on organizational members' behaviors also, the charisma and clear vision of these executives have profound effects on the entire organization (de Vries et al., 2002; Wang, Tsui \& Xin, 2011). Therefore, on individual level, it becomes almost difficult to calculate the effects of managers on employees' behaviors (Groves \& Feyerherm, 2011). However, at operational level, influence of immediate supervisors on employees' behaviors and motivation is so much obvious. (Groves \& Feyerherm, 2011; Wang et al., 2010). Historically, characteristics and capabilities of leaders have long been a topic of interest in leadership studies. The trait theory of leadership was proposed to emphasize that the leader is the central person who integrates the group and possesses the greatest number of desirable personality traits (Zaccaro et al., 2004). However, dissatisfaction with inadequately addressing how leadership traits influence followers and their work, the behavior theory was developed to expand the leadership concept beyond the perspective of personal traits. The most famous study of behavior theory conducted by the Ohio State leadership studies helped to develop the constructs of initiating structure and consideration of leadership (Judge et al., 2004). In the 1970s, theorists became more focused on the study of effective leadership behaviors (Chemers, 2000). One well-known theory is contingency theory, which stated that leadership behaviors vary from situation to situation. Other research showed (Vecchio et al., 2008) that the effective leader indicates, through a series of transactions with followers, the path they need to follow to achieve the valued goals. Currently, the field of leadership research is in transition regarding the essential behaviors of leaders, shifting from earlier versions of initiating structure, consideration, and transactional leaders to transformational leaders (Sumner et al., 2006). The transformational leadership theory was derived from Barbuto (2005) qualitative classification of transactional and transformational political leaders and was extended by Frittz (2005). Transactional leadership, based on relationship between leader-follower is series of exchanges or bargains between leaders and followers. On the other hand, transformational leadership emphasizes the changes leaders instill in their followers by raising the perspectives of their needs and by providing opportunities for them to develop capabilities (Frittz, 2005). Unlike the traditional leadership theories that focused on rational processes, the transformational leadership theory emphasizes emotions and values (Howell \& Shamir, 2005). Thus, this study in context of contemporary 
organizations focuses on combining these three theories in a research framework to determine the effective leadership process. In continuity, Avolio, (2010) have conceptualized full-range leadership theory which includes the existence of and constellation of leadership style or behaviors, ranging transformational behaviors to laissez fair (those who basically do nothing while expecting results from the followers). A large number of studies have been conducted to investigate the influence of leadership on different kinds of organizational settings, such as businesses (Bass \& Bass, 2009; Howell et al., 2005; Rubin et al., 2005; Leban \& Zulauf, 2004; Humphreys \& Einstein, 2003 Anvari et al., 2013; Anvari et al., 2014). Similarity large number of studies have been conducted to investigate the influence of leadership on followers outcomes such as job performance (Halldorsson and Offermann, 1999; Anvari and Amin, 2010; Hayward, 2006; Hernandez, 2010; Shahhosseini et al., 2013), and job satisfaction (Spinelli, 2004; Tsai, 2008, Rafferty \& Griffin, 2004). Few studies have actually tested the relationship between leadership style (full range leadership style) and OC (Spinelli, 2004; Vecchio et al., 2008; Shahhosseini et al., 2013; Anvari, 2014). Previous work has found links between transformational leadership behavior of managers and both task (Howell et al., 2005; Rickards \& Moger, 2006) and citizenship performance (Rubin et al., 2005; Boerner et al., 2007; Babcock-Roberson \& Strickland, 2010; Boerner et al., 2007; Rubin et al., 2005; Babcock-Roberson \& Strickland, 2010) of subordinates. Also previous work has found links between transformational and (Geijsel et al., 2003) transactional leadership behavior and increased job satisfaction for followers, increase motivation toward extra effort for followers, and perceived leaders effectiveness. Many studied about the relationship between leadership and performance show that is a strong relationship exist between transformational leadership and performance (Leithwood \& Jantzi, 2005). Thomas (2004) demonstrated that, capability of continuous adaptation with individuals from different cultures and ability to manage inter-cultural relations is of importance among required skills. This ability called cultural intelligence (CQ). Working in international workplace needs familiar people to different cultures who could relate with people from other cultures. According to the definitions of cultural intelligence, it is clearly defined that since a manager possesses different cultural backgrounds with various people in all over the world, it may be possible for him to create serious contradiction in exposure with different people with various cultures. Indeed, the lack of cultural intelligence in culturally diverse business environments among leaders have adverse effects on workplace successes, team effectiveness (Ng, 2011; Kim \& Van Dyne, 2012), cross cultural leadership (Dekker et al., 2008; Deng and Gibson, 2008), productivity (Earley et al., 2006); (Ang \& Inkpen, 2008) and business competence (Janssens \& Brett, 2006). Empirical research on cultural intelligence is rapidly growing and has been the focus of recent research on the effective functioning of foreign professional executive (Ang et al., 2007; Lee, 2010; Tay et al., 2000) and international adjustment (Templer et al., 2006). Few major studies that have dealt with the relationship between cultural intelligence and OC (Lee \& Sukoco, 2010; Rose et al., 2010; Ang et al., 2007; Ang et al., 2006; Anvari, 2014). In all these studies it was found that there is a significant positive relationship between $\mathrm{CQ}$ and job performance, implying that greater the level of $\mathrm{CQ}$, greater the level of job performance. Griffin et al. (2007) argued that meeting the role expectations is an important element in the assessment of individual job performance. Stone-Romero et al. (2003) further stated that in the international assignments, individuals often receive poor job performance evaluation from their superiors when they have a different cultural background, do not understand cultural differences in role expectations, and do not conform to role expectations. It should be noticed that many managers who are successful in cultural environment would encounter with efficiency and effectiveness by entering a strange environment while some others, by changing the cultural environment, are able to adapt their performance with the new conditions easily (Triandis, 2006). On the other hand, in the world competition field, many of the organizations have changed their leadership style from a transactional leadership approach to a transformational one so that they could achieve their goals and strategies. So one of the subjects which the managers should change along changing the conditions is their leadership method and the next subject is learning the proper and new capabilities that one of them is cultural intelligence (Dean, 2007). This is not is not out of mind that the managers with high cultural intelligence tend to the close and powerful behavior methods. In addition, leaders that have cultural intelligence increase organizational commitment (OC). Conducting this study on the effects of leadership style on OC with the role of cultural intelligence will help leaders to develop higher commitment and better organizational outcomes.

\subsection{Cultural Intelligence and $O C$}

Successful leadership in modern organizations become more and more upon cultural intelligence leadership (Rockstuhl et al., 2011). Leaders with high CQ may make possible the satisfaction and performance of their employee by the considerate the impact of cultural values one brings to the workplace, being able to analyze and adapt suitable leadership style and prospect to specific cross-cultural situation, and recognize the weaknesses of the different personal represented by culturally diverse workers (Stone-Romero \& Stone, 2005). In addition, manger's CQ will have and more positive impact on job performance with employee with low CQ than for 
employee with high CQ. Therefore, employee with high CQ requires less managerial interference. Employee with low CQ may be less adapt in this skills, and may more advantage more from managerial interference that help them better manage cultural opportunity in thinking and behaviors that lead to more confidence, sense of control, and positive interaction, that translate to higher commitment and performance. This study goes forward to support the conceptual content proposed by Anvari et al. (2014), who initially mentioned that the relationship between workplace CQ and outcomes could be tied directly with positive employee attitudes. Therefore, the aim in this paper was to evaluate the association between CQ and OC as a positive behavioural outcome (Figure 1).

$\boldsymbol{H}$ : There is a significant and positive relationship between cultural intelligence and organizational commitment.

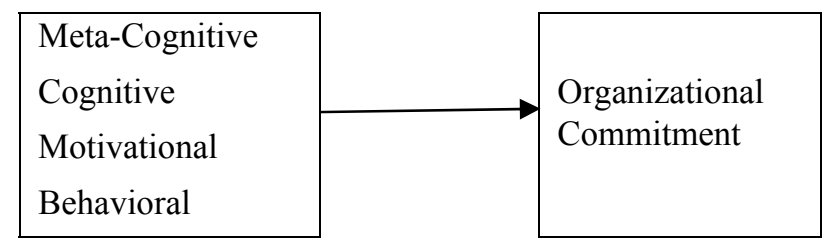

Figure 1. Conceptual framework

\section{Method}

\subsection{Design}

This study is a descriptive correlational survey that utilized quantitative methodology to investigate the association between four dimensions of $\mathrm{CQ}$, meta-cognitive $\mathrm{CQ}$, cognitive $\mathrm{CQ}$, motivational $\mathrm{CQ}$, and behavioral CQ and Organisational Commitment. In this cross-sectional study, a questionnaire-based survey method was used for data collection.

\subsection{Population and Sampling}

There is total of 310 faculty members in University Technology Malaysia (UTM) that 14 of them were chosen to answer the survey questionnaire. Respondents of this study include 310 from 1654 academic staff who are working full time in University Technology Malaysia Skudi (UTM).

\subsection{Measurements}

Two survey instruments were used in the current study to assess emotional intelligence and organizational commitment. Respondents were also requested to supply information about their qualifications, gender, working experience, age and occupation status. And also, rice and ranking of his/her job for head of department.

\subsubsection{Cultural Intelligence Scale (CQS)}

The Cultural Intelligence Scale (CQS) was used to measure the four dimensions of cultural intelligence (Ang, 2007) The 20-item scale (Appendix C) CQS was composed of the meta-cognitive CQ, cognitive CQ, motivational CQ, and behavioral CQ factors and used a 5 point Likert-type scale ranging from $(1=$ "strongly disagree" and 5 "strongly agree") for subjects to select the belief that corresponds best to their cultural beliefs (Ang et al., 2007; Van Dyne et al., 2008). According to (Ang et al., 2005) confirmatory factor analysis yielded good validity and reliability. All four subscales (Meta-cognition CQ $(\alpha=.76)$; Cognitive CQ $(\alpha=.84)$; Motivation CQ $(\alpha=.77)$; and Behavioral CQ $(\alpha=.84))$ had high Cronbach alpha values. In the present study, Cronbach alpha coefficients for each subscale were Meta-cognition CQ $(\alpha=.83)$; Cognitive CQ $(\alpha=.89)$; Motivation CQ $(\alpha=.85)$; Behavioral CQ $(\alpha=.87)$, and an overall Cronbach alpha coefficient $(\alpha=.90)$.

\subsubsection{Organizational Commitment (OCS)}

This questionnaire has been written by Mayer and Allen (Salovey \& Sluyter, 1997) and included 18 items. OCS is divided into 3 categories: effective commitment, commitment, and normative commitment, in 7 Likert scales and 6 sub-scales. Reliability of the inventory was estimated 3.10 by the Cronbach's alpha coefficient.

\subsection{Methods of Data Analysis}

All data were analysed using the Statistical Package of Social Sciences (SPSS) software version 16 (SPSS, Inc., Chicago, IL, USA). Descriptive statistics were used to analyse demographic variables as well as other variables. Pearson's correlation analysis was run to test the correlations between all independent and dependent variables. To examine the relationship between CQ dimensions and OC, multiple regression was conducted. 


\section{Results}

\subsection{Relationship between CQ Dimensions and Organizational Commitment}

As Pearson's correlation analysis was conducted in the study, the results exhibited the following: (H1a) there

was a significant correlation of the positive influence of meta-cognitive CQ on the organizational commitment(r $=0.390, \mathrm{P}<0.001)$. (H1b) there was a significant correlation of the positive effect of cognitive CQ on the organizational commitment $(\mathrm{r}=0.363, \mathrm{P}<0.001)$. $(\mathrm{H} 1 \mathrm{c})$ there was a significant correlation in the positive effect of motivational CQ on organizational commitment $(\mathrm{r}=0.356, \mathrm{P}<0.001)$. In addition, there was a significant correlation of the positive influence of behavioral CQ factors on the organizational commitment $(\mathrm{r}=0.401, \mathrm{P}<$ 0.001 )(Table1). Regression analysis also revealed that CQ explained $20 \%$ of the variation in the organizational commitment.

Table 1. Person correlation between (meta-cognitive CQ, cognitive CQ, motivational CQ, and behavioral CQ factors and $\mathrm{OC}$

\begin{tabular}{llllll}
\hline & MCCQ & CCQ & MCQ & BCQ & OC \\
\hline MCCQ & $\mathbf{1}$ & & & & 0.390 \\
CCQ & 0.431 & $\mathbf{1}$ & & 0.363 \\
MCQ & 0.533 & 0.745 & $\mathbf{1}$ & $\mathbf{1}$ & 0.356 \\
BCQ & 0.345 & 0.445 & 0.375 & & 0.401 \\
OC & & & & $\mathbf{1}$ \\
\hline
\end{tabular}

\section{Discussion}

First of all, this study aimed to determine the CQ level of UTM leaders. CQ in this study is consists of four dimensions which are meta-cognitive, cognitive, motivational, behavioral factors and OC. CQ level of UTM leaders were evaluated by their subordinates (academic staff). The result showed that leaders require an ability to adapt to a variety of cultural situations, this ability called cultural intelligence (CQ). Indeed, leader's effectiveness and success is largely dependent on the ability to adapt to the various cultural contexts. (Earley and Ang, 2003). When leaders learn to effectively and respectfully interact with people from diverse cultures, we strike a gold mine of opportunity for personal and professional fulfillment (Livermore, 2011). Cultural intelligence offers leaders an overall selection and perspective that can be applied to a numerous of cultural situations. It is a capability that includes four different dimensions that enabling us to meet the fast-paced demands of leadership. Cognitive reflects knowledge of the norms and practices in the host culture developed from training, education, and personal experiences. Meta-cognitive individual's ability to control their thought processes relating to culture. The motivation facet reflects the individual's capability to learn about and desire to adapt in culturally diverse settings. Behavior refers to the behaviors that a person engages in and reflects a person's capability to acquire or adapt behaviors appropriate for new culture. Thus, this study adds to the expanding homological network of cultural intelligence by determining which factor (meta-cognitive, cognitive, motivation, behavior) best predicts leadership. It also answers the challenge to consider cultural intelligence as a multidimensional construct and examine what specific dimensions of cultural intelligence have relevance to different outcomes.

\section{Acknowledgments}

The authors would like to acknowledge Siavash Hosseinpour Chermahini for encouragement, motivation and full support. Special thanks to all FM members.

\section{References}

Ang, S., \& Inkpen, A. C. (2008). Cultural Intelligence and Offshore Outsourcing Success: A Framework of Firm - Level Intercultural Capability. Decision Sciences, 39(3), 337-358. http://dx.doi.org/10.1111/j.1540-5915. 2008.00195.x

Ang, S., Van Dyne, L.,\& Koh, C. (2006). Personality correlates of the four-factor model of cultural intelligence. Group \& Organization Management, 31(1), 100-123. http://dx.doi.org/10.1177/1059601105275267

Ang, S., Van Dyne, L., Koh, C., Ng, K. Y., Templer, K. J., Tay, C., \& Chandrasekar, N. A. (2007). Cultural 
intelligence: Its measurement and effects on cultural judgment and decision making, cultural adaptation and task performance. Management and Organization Review, 3(3), 335-371. http://dx.doi.org/10.1111/j.17408784.2007.00082.x

Anvari, R., Huzaid, N. S. B. J., Miri, S. A., \& Chermahini, S. H. (2013). Mediating effect of psychological contract in the relationship between learning and development initiatives and engineers' intention to stay. Review of European Studies, 5(5), 233-237. http://dx.doi.org/10.5539/res.v5n5p233

Anvari, R., \& Amin, S. B. M. (2010). The customer relationship management strategies: Personal needs assessment of training and customer turnover. European Journal of Social Sciences, 14(1), 17-33.

Anvari, R., Irum, S., Shah, I. M., Mahmoodzadeh, N., \& Ashfaq, M. (2014). Determinants of information technology leadership program. Review of European Studies, 6(2), 45-49. http://dx.doi.org/10.5539/res. v6n2p45

Avolio, B. J. (2010). Full range leadership development. Sage.

Babcock-Roberson, M. E., \& Strickland, O. J. (2010). The relationship between charismatic leadership, work engagement, and organizational citizenship behaviors. The Journal of Psychology, 144(3), 313-326. http://dx.doi.org/10.1080/00223981003648336

Barbuto, J. E. (2005). Motivation and transactional, charismatic, and transformational leadership: A test of antecedents. Journal of Leadership \& Organizational Studies, 11(4), 26-40. http://dx.doi.org/10.1177/ 107179190501100403

Bass, B. M., \& Bass, R. (2009). The Bass handbook of leadership: Theory, research, and managerial applications. Simon and Schuster.

Berson, Y., Nemanich, L. A., Waldman, D. A., Galvin, B. M., \& Keller, R. T. (2006). Leadership and organizational learning: A multiple levels perspective. The Leadership Quarterly, 17(6), 577-594.

Bodla, M. A. (2010). Need For Leadership: Empirical Evidence From Pakistan. International Journal of Management \& Information Systems, 14(5).

Boerner, S., Eisenbeiss, S. A., \& Griesser, D. (2007). Follower behavior and organizational performance: The impact of transformational leaders. Journal of Leadership \& Organizational Studies, 13(3), 15-26. http://dx.doi.org/10.1177/10717919070130030201

Chemers, M. M. (2000). Leadership research and theory: A functional integration. Group Dynamics: Theory, research, and practice, 4(1), 27. http://dx.doi.org/10.1037/1089-2699.4.1.27

de Vries, R. E., Roe, R. A., \& Taillieu, T. C. (2002). Need for leadership as a moderator of the relationships between leadership and individual outcomes. The Leadership Quarterly, 13(2), 121-137. http://dx.doi.org/10.1016/S1048-9843(02)00097-8

Dean, B. P. (2007). Cultural intelligence in global leadership: A model for developing culturally and nationally diverse teams. ProQuest.

Dekker, D. M., Rutte, C. G., \& Van den Berg, P. T. (2008). Cultural differences in the perception of critical interaction behaviors in global virtual teams. International Journal of Intercultural Relations, 32(5), 441-452. http://dx.doi.org/10.1016/j.ijintrel.2008.06.003

Deng, L., \& Gibson, P. (2008). A qualitative evaluation on the role of cultural intelligence in cross-cultural leadership effectiveness. International journal of leadership studies, 3(2), 181-197.

Earley, P. C., Ang, S., \& Tan, J. -S. (2006). CQ: Developing cultural intelligence at work. Stanford University Press.

Frittz, H. (2005). Transformational, transactional, and laissez-faire leadership: an examination of the Bass (1985) theory in the university classroom environment (Unpublished doctoral dissertation). Capella University, Minneapolis, MN.

Geijsel, F., Sleegers, P., Leithwood, K., \& Jantzi, D. (2003). Transformational leadership effects on teachers' commitment and effort toward school reform. Journal of Educational Administration, 41(3), 228-256. http://dx.doi.org/10.1108/09578230310474403

Groves, K. S. and Feyerherm, A. E. (2011). Leader Cultural Intelligence in Context Testing the Moderating Effects of Team Cultural Diversity on Leader and Team Performance. Group \& Organization Management, 36(5), 535-566. 
Hayward, B. A. (2006). Relationship between employee performance, leadership and emotional intelligence in a South African parastatal organisation. Rhodes University

Hernandez, B. J. (2010). The relationship between leadership styles and performance success in hospitals. Walden University

Hollander, E. P., \& Offermann, L. R. (1990). Power and leadership in organizations: Relationships in transition. American psychologist, 45(2), 179. http://dx.doi.org/10.1037/0003-066X.45.2.179

Horwitz, I. B., Horwitz, S. K., Daram, P., Brandt, M. L., Charles Brunicardi, F., \& Awad, S. S. (2008). Transformational, transactional, and passive-avoidant leadership characteristics of a surgical resident cohort: analysis using the multifactor leadership questionnaire and implications for improving surgical education curriculums. Journal of Surgical Research, 148(1), 49-59

Howell, J. M., Neufeld, D. J., \& Avolio, B. J. (2005). Examining the relationship of leadership and physical distance with business unit performance. The Leadership Quarterly, 16(2), 273-285.

Humphreys, J. H., \& Einstein, W. O. (2003). Nothing new under the sun: Transformational leadership from a historical perspective. Management Decision, 41(1), 85-95. http://dx.doi.org/10.1108/00251740310452934

Janssens, M., \& Brett, J. M. (2006). Cultural Intelligence in Global Teams A Fusion Model of Collaboration. Group \& Organization Management, 31(1), 124-153.

Judge, T. A., Piccolo, R. F., \& Ilies, R. (2004). The forgotten ones? The validity of consideration and initiating structure in leadership research. Journal of applied psychology, 89(1), 36. http://dx.doi.org/10.1108/00251 740310452934

Kim, Y. J., \& Van Dyne, L. (2012). Cultural intelligence and international leadership potential: The importance of contact for members of the majority. Applied psychology, 61(2), 272-294.

Leban, W. and Zulauf, C. (2004). Linking emotional intelligence abilities and transformational leadership styles. Leadership \& Organization Development Journal, 25(7), 554-564.

Lee, L. -Y., \& Sukoco, B. M. (2010). The effects of cultural intelligence on expatriate performance: The moderating effects of international experience. The International Journal of Human Resource Management, 21(7), 963-981.

Leithwood, K., \& Jantzi, D. (2005). A review of transformational school leadership research 1996-2005. Leadership and policy in schools, 4(3), 177-199. http://dx.doi.org/10.1080/15700760500244769

Livermore, D. (2011). The Cultural Intelligence Difference Special Ebook Edition: Master the One Skill You Can't Do Without in Today's Global Economy. AMACOM Div American Mgmt Assn.

Ng, P. S. (2011). Cultural Intelligence and Collective Efficacy in Virtual Team Effectiveness. 1495650. Minnesota State University, Mankato Ann Arbor

Pieterse, A. N., Van Knippenberg, D., Schippers, M., \& Stam, D. (2010). Transformational and transactional leadership and innovative behavior: The moderating role of psychological empowerment. Journal of Organizational Behavior, 31(4), 609-623. http://dx.doi.org/10.1002/job.650

Rickards, T., \& Moger, S. (2006). Creative leaders: a decade of contributions from Creativity and Innovation Management Journal. Creativity and Innovation Management, 15(1), 4-18. http://dx.doi.org/10.1111/j. 1540-4560.2011.01730.x

Rockstuhl, T., Seiler, S., Ang, S., Van Dyne, L., \& Annen, H. (2011). Beyond General Intelligence (IQ) and Emotional Intelligence (EQ): The Role of Cultural Intelligence (CQ) on Cross - Border Leadership Effectiveness in a Globalized World. Journal of Social Issues, 67(4), 825-840.

Rose, R. C., Sri Ramalu, S., Uli, J., \& Kumar, N. (2010). Expatriate Performance in International Assignments: The Role of Cultural Intelligence as Dynamic Intercultural Competency. International Journal of Business \& Management, 5(8).

Rubin, R. S., Munz, D. C., \& Bommer, W. H. (2005). Leading from within: The effects of emotion recognition and personality on transformational leadership behavior. Academy of Management Journal, 48(5), 845-858.

Salovey, P., \& Sluyter, D. J. (1997). Emotional development and emotional intelligence: Educational implications. Basic Books.

Shahhosseini, M., Daud Silong, A., \& Arif Ismaill, I. (2013). Relationship between transactional, transformational leadership styles, emotional intelligence and job performance. Researchers World: Journal 
of Arts, Science \& Commerce, 4(1).

Stone - Romero, E. F., Stone, D. L., \& Salas, E. (2003). The influence of culture on role conceptions and role behavior in organisations. Applied Psychology, 52(3), 328-362. http://dx.doi.org/10.1111/1464-0597.00139

Sumner, M., Bock, D., \& Giamartino, G. (2006). Exploring the linkage between the characteristics of IT project leaders and project success. Information Systems Management, 23(4), 43-49.

Templer, K. J., Tay, C., \& Chandrasekar, N. A. (2006). Motivational cultural intelligence, realistic job preview, realistic living conditions preview, and cross-cultural adjustment. Group \& Organization Management, 31(1), 154-173.

Thomas, D. C., \& Inkson, K. (2004). Cultural intelligence. Berrett-Koehler San Francisco.

Triandis, H. C. (2006). Cultural intelligence in organizations. Group \& Organization Management, 31(1), 20-26.

Vecchio, R. P., Justin, J. E., \& Pearce, C. L. (2008). The utility of transactional and transformational leadership for predicting performance and satisfaction within a path - goal theory framework. Journal of Occupational and Organizational Psychology, 81(1), 71-82. http://dx.doi.org/10.1348/096317907X202482

Wang, F.-J., Shieh, C., \& Mei-Ling, T. (2010). Effect of leadership style on organizational performance as viewed from human resource management strategy. African Journal of Business Management, 4(18), 3924-3936.

Zaccaro, S. J., Kemp, C., \& Bader, P. (2004). Leader traits and attributes. The nature of leadership, 101, 124.

\section{Copyrights}

Copyright for this article is retained by the author(s), with first publication rights granted to the journal.

This is an open-access article distributed under the terms and conditions of the Creative Commons Attribution license (http://creativecommons.org/licenses/by/3.0/). 